\title{
INTAKE OF DIETARY FIBRE AND ITS SOURCES RELATED TO ADOLESCENTS' AGE AND GENDER BUT NOT TO THEIR WEIGHT
}

\author{
Justyna W. Wuenstel, Lidia Wądołowska, Małgorzata A. Słowińska, Ewa Niedźwiedzka, Joanna Kowalkowska, \\ Lidia Kurp \\ Department of Human Nutrition, University of Warmia and Mazury, Olsztyn, Poland
}

\begin{abstract}
SUMMARY
Aim: The aim of this observational study was to investigate the intake of dietary fibre and its sources among Polish adolescents according to prevalence of overweight after adjustment for age and gender.

Method: The study sample consisted of 1,565 students, including $48 \%$ boys and $52 \%$ girls aged 13-18 with normal weight, overweight and obesity. Dietary information was reported using the Block Screening Questionnaire for Fruit/Vegetable/Fibre Intake. The nutritional status was assessed on the basis of body mass and height measurements. The statistical analysis used one-factor logistic regression, multiple linear regression, trend estimation and a comparison of mean values.

Results: Adolescents consuming white bread and rolls with a frequency $\geq 4$ times/week had $\mathrm{OR}=0.74(95 \% \mathrm{Cl} 0.56-0.97)$ for overweight and obesity compared to adolescents with less frequent consumption. For other fibre sources and overall dietary fibre no significant differences were noted in consumption frequency between adolescents with normal weight and overweight/obesity. Overall, boys were more often overweight and obese than girls. Girls had a higher intake of dietary fibre, fruit, fresh vegetables, dark bread and rolls, and lower intake of potatoes, beans and white bread and rolls than boys. Older age was associated with a decrease in the consumption of fruit juices, fruit, potatoes, white bread and rolls, and dietary fibre in girls and a decrease in fruit and fresh vegetable consumption in boys.

Conclusion: The intake of dietary fibre was not associated with the prevalence of overweight. As to the fibre sources, only a higher consumption of white bread and rolls decreased the chance of the occurrence of adolescent overweight. The consumption of dietary fibre and its sources was related to the age and gender of adolescents.
\end{abstract}

Key words: adolescent, age, gender, dietary fibre, fibre sources, overweight

Address for correspondence: J. W. Wuenstel, Department of Human Nutrition, University of Warmia and Mazury, UI. Słoneczna 45f, 10-718, Olsztyn, Poland. E-mail: justyna.wuenstel@uwm.edu.pl

http://dx.doi.org/10.21101/cejph.a4331

\section{INTRODUCTION}

Nutrition is one of the most important factors that influence public health. Dietary habits shaped during the childhood and adolescence periods persist to adulthood and subsequently influence adult health $(1,2)$. In addition to a genetic predisposition to like sweet and salty flavours and dislike bitter and sour flavours and other innate, automatic mechanisms of appetite regulation, food preferences are shaped by the children's environment, which is mostly created by their parents (3). However, parental behaviour designed to encourage or restrict children's diets can have the opposite effect (4). During adolescence, young people begin to independently make decisions about food intake and begin to reveal the impact of individual factors such as gender, age, etc. (5). The magnitude of changes taking place during adolescence, including the development of eating habits and changes in nutritional status, make this period critical for building good health and avoiding health consequences associated with improper nutrition.

An important health problem is the high prevalence of obesity in both children and adults. Additionally, obesity in childhood is strongly predictive of obesity in adulthood (6). Obesity is mainly the result of a positive energy balance, although other dietary factors can also directly or indirectly influence energy intake. A high intake of dietary fibre helps to reduce the absorption of macronutrients and the overall energy density of the diet $(7,8)$. Furthermore, a high consumption of dietary fibre, through different mechanisms, enhances satiety and decreases subsequent hunger $(7,8)$. Despite a large number of studies, the role of fibre in the prevalence of obesity remains uncertain. Differences in the definition of fibre and the physiological effects of various types of fibre make it difficult to estimate the ultimate results (8). Studies on fibre supplementation also have conflicting results indicating that fibre can help to reduce weight or that it does not have any influence on weight at all $(7,9,10)$.

Most adolescents usually consume an insufficient quantity of dietary fibre, despite positive reports on the impact of fibre on health $(2,11,12)$. Insufficient dietary fibre intake is a result of decreasing consumption of fruit and vegetables in adolescents (13). It is estimated that an inadequate consumption of fruit and vegetables is the cause of 2.635 million deaths per year worldwide 
(14). The consumption of fruit and vegetables in amount greater than $600 \mathrm{~g}$ per day can reduce the total worldwide burden of ischaemic heart disease by $31 \%$, ischaemic stroke by $19 \%$ and from $2 \%$ to $20 \%$ of cancer depending on its origin (14). Foods rich in dietary fibre are usually lower in energy, fat and sugar, and overall have a higher nutritional density (8). Thus, higher consumption of fruit and vegetables is associated with lower energy intake and higher fibre intake plays the most important role in weight management (15). A literature review of intervention studies found that increasing consumption of fruit and vegetables with simultaneous reduction of fat intake in most cases lead to a reduction in body weight (15). However, independent increase in the consumption of fruit and vegetables ad libitum is not associated with a reduction in body weight. It might even contribute to weight gain (15).

The evidence indicates that the positive influence of high dietary fibre and its sources on adolescents' weight is very limited. Thus, the aim of the study was to assess the impact of the consumption frequency of dietary fibre and source of intake on the prevalence of overweight (including obesity) among girls and boys aged $13-18.9$ years.

\section{MATERIALS AND METHODS}

The prevalence of overweight was assessed based on height and weight measurements. Adolescents' weight and height were measured with an accuracy to $0.1 \mathrm{~kg}$ and $0.5 \mathrm{~cm}$. The BMI was calculated for each subject and interpreted according to the Polish growth references for school-aged children and adolescents from 2010 (16). The normal weight group included adolescents in the $\mathrm{BMI}=5-84$ percentile, the overweight group were in the $\mathrm{BMI}=$ $85-94$ percentile and the obese group were in the BMI $\geq 95$ percentile. Due to the low number of subjects in the obese group (n 78), the statistical analysis was carried out on a combined group of overweight and obese adolescents $(\mathrm{n}=286)$.

Information on the consumption frequency of various dietary sources of fibre was collected by a validated Block questionnaire (17). The questionnaire contains nine questions on food groups and dishes, which contain one of the following components: fruit juices, fruit, fresh vegetables, beans, potatoes, other vegetables, white bread and rolls, dark bread and rolls, high-fibre or bran cereals. The frequency of consumption was expressed by five categories which were assigned the points as follows: less often than once a week ( 0 points), once a week (1 point), 2-3 times per week ( 2 pts.), 4-6 times per week ( 3 pts.) and every day (4 pts.). For each person, the points were summed and the fibre intake was expressed on a point scale ( $0-36$ points). On the basis of the total number of points, respondents were categorized into three following groups: satisfactory fibre intake ( $\geq 30$ pts.), insufficient fibre intake (20-29 pts.) and fibre-poor $\operatorname{diet}(<20$ pts.).

\section{Sample Collection}

The observational study was conducted in 2010-2011 on a convenience sample of middle- and high-school students. The consent of school principals and parents to participate in the research was obtained prior to the study. The study sample was designed in a way to ensure adequate numbers of persons in every age and gender subgroup (quota sampling). The study was carried out in areas of northern, eastern and central Poland in five regions: Warmia and Mazury (61\%), Mazowieckie (23\%), Kujawsko-Pomorskie (6\%), Podlaskie (6\%), and Lodzkie (5\%). Young people came from areas with various degrees of urbanisation: rural (42\%), small towns $(<100,000$ citizens) $(36 \%)$, and large cities $(\geq 100,000$ citizens) $(22 \%)$.

Trained interviewers carried out the questioning (via hall testing) and anthropometric measurements of height and body weight. Although the students were familiarized with how to fill in the questionnaires, 787 questionnaires were incomplete or incorrect (about $30 \%$ of the initial sample), and they were excluded from the analysis. Since the study focused only on adolescents with overweight (study group) and normal weight (control group), children with underweight $\left(\mathrm{BMI}=18.5-20.0 \mathrm{~kg} / \mathrm{m}^{2} ; \mathrm{n}=107\right)$ and those with malnutrition (BMI $<18.5 \mathrm{~kg} / \mathrm{m}^{2} ; \mathrm{n}=33$ ) were excluded from further analysis (overall $5.4 \%$ of the initial sample). Adolescents with too high age ( $\geq 19$ years) or too low age $(<13$ years) were excluded as well $(n=80,3.1 \%$ of the initial sample). A very small number of participants with satisfactory fibre intake $(n=28$, $1.1 \%$ of initial sample) was recorded, which was the reason for excluding them from further analysis.

\section{Initial Sample of Adolescents}

The initial sample consisted of 2,600 adolescents. Exclusion criteria from further research were missing or incorrect values in questionnaire $(n=787)$; too high or low age $(n=80)$; underweight or malnutrition $(n=140)$; and high fibre intake $(n=28)$.

\section{Final Sample of Adolescents}

In total, 1,565 young people ( $60.2 \%$ of initial sample), including 753 boys (48\%) and 812 girls (52\%) were classified. Most adolescents $(81.7 \%$ of the sample, n 1,279$)$ had normal weight, whereas $13.3 \%(n=208)$ were overweight and $5 \%$ were obese $(\mathrm{n}=78)$. Relatively more girls than boys had normal weight ( $84.1 \%$ vs. $79.2 \%$, respectively), although fewer girls than boys were overweight $(11.2 \%$ vs. $15.5 \%)$ or obese $(4.7 \%$ vs. $5.3 \%)$. According to the initial quota sampling, the percentage of boys and girls in the three age subgroups was similar, i.e.: $37.9 \%$ of boys and $38.7 \%$ of girls in the youngest group (13-14.9 years), $30.3 \%$ and $30.3 \%$ in the middle group (15.0-16.9 years), and $31.9 \%$ and $31.0 \%$ in the oldest group (17.0-18.9 years).

\section{Statistical Analysis}

Statistical analyses were performed for the total sample, gender groups, two weight groups (normal weight and overweight) and for three age groups (13-14.9 years, 15-16.9 years and 17.0-18.9 years). The arithmetic mean values were calculated for the consumption frequencies of fibre sources with points assigned to consumption categories (from 0 pts. for less than one a week to 4 pts. for every day) and for dietary fibre as the sum of the points (from 0-36 pts.). Mean values were shown with $95 \%$ confidence intervals and compared using the Kruskal-Wallis test. Trend estimation was used for the assessment of changes in consumption frequencies with increasing age. The trends were evaluated with a Spearman regression test and were marked as a decreasing trend $(\downarrow)$ or increasing trend $(\uparrow)$. The multiple linear regression model 
quantified the relationship between 12 independent variables (gender, age, BMI, food sources of fibre) and the dependent variable (total dietary fibre intake). The coefficients of determination for the model were $\mathrm{R}=0.79$ and $\mathrm{R}^{2}=0.63$. One-factor logistic regression was also used, where the OR values were adjusted for gender and age. The reference group were young people with normal weight $(\mathrm{OR}=1.00)$. Wald statistics were used in the assessment of OR values. All statistical analyses were carried out using STATISTICA 10.0 PL, software by StatSoft.

\section{RESULTS}

In the total sample, girls compared to boys had significantly higher mean values of the consumption frequency of fruit $(2.71$ vs. 2.50 pts., respectively), fresh vegetables ( 2.17 vs. 2.00 pts.), dark bread and rolls (1.51 vs. 1.26 pts.) and lower mean values of the consumption frequency of beans ( 0.58 vs. 0.72 pts.) and potatoes ( 2.77 vs. 2.89 pts.) (Table 1). There was a higher mean value of dietary fibre among girls than in boys (18.7 vs. 18.2 pts.) In the adolescents with normal weight, girls compared to boys had significantly higher mean values of the consumption frequency of fruit (2.72 vs. 2.52 pts.), fresh vegetables (2.16 vs. 1.97 pts.), dark bread and rolls (1.48 vs. 1.25 pts.), overall dietary fibre (18.8 vs. $18.3 \mathrm{pts}$.), and lower mean values of the consumption frequency of beans ( 0.59 vs. 0.69 pts.) and potatoes ( 2.79 vs. 2.91 pts.) (Table 1). In the adolescents with overweight and obesity, girls compared to boys had significantly higher mean values of the consumption frequency of dark bread and rolls (1.65 vs. 1.28 pts.) and lower consumption frequency of beans ( 0.54 vs. 0.85 pts.) (Table 1$)$.

In the statistical comparisons of adolescents with normal weight versus overweight and obese adolescents, no differences were found in the consumption frequency of dietary fibre or its source for adolescents in general or for gender groups (Table 1). Only the consumption frequency of white bread and rolls had a significant influence on weight. Adolescents who consumed white bread and rolls with a frequency $\geq 4$ times per week had an $\mathrm{OR}=0.74(95 \% \mathrm{CI} 0.56-0.97)$ for high BMI value $(>85$ percentile) compared to adolescents with less frequent consumption (Table 2). After adjusting for gender and age, the OR values dropped a little from 0.74 to 0.72 (95\% CI $0.55-0.97)$ for gender, 0.73 (95\% CI $0.55-0.95)$ for age and 0.72 (95\% CI $0.54-0.94)$ for gender and age together (Table2).

In general, among boys in total and boys with normal weight we noted a decreasing trend of fruit consumption with increasing age (Table 1), whilst among the girls in total and girls with normal weight we noted decreasing trends of the consumption of fruit juices, fruit, potatoes, white bread and rolls, and overall dietary fibre and increasing trends of dark bread and rolls consumption. Among adolescents with overweight, no significant changes in consumption frequencies with increasing age were found. The associations of total dietary fibre intake with adolescent age and food sources of fibre were analysed with a regression model (Table $3)$. The highest slope in the model was obtained for the consumption of dark bread and rolls $(\beta=0.24)$, while the lowest slope was obtained for bean consumption $(\beta=0.13)$. There was a negative slope for age with increasing dietary fibre intake $(\beta=-0.05)$. Gender and BMI of adolescents were not significantly related to the intake of dietary fibre.

\section{DISCUSSION}

An increase in age was correlated with a decrease in dietary fibre intake among adolescents. However, in the USA, adolescent and adult intake of dietary fibre increased with the age of participants, which may be due to the promotion of health benefits of dietary fibre (18). The drop in fibre intake was due to a decrease in the consumption of its sources and the changes were noted more often in girls than boys. Girls from older groups less frequently consumed fruit juices, fruits, potatoes, white bread and rolls, and overall dietary fibre and more frequently consumed dark bread and rolls. In boys, there was only a decreasing trend of fruit consumption with increasing age. During adolescence, the impact of exogenous factors (i.e. food advertisement or influence of peers) increases, whereas the impact of endogenous factors (i.e. food taste) decreases and the parental influence and control of what young people consume also begins to decrease (5). All of this may cause a decline in the consumption of dietary fibre and its sources.

The results confirmed that gender and age played an important role in the consumption frequencies of dietary fibre and its sources. The food choice motives are highly dependent on gender and age, both in adults and adolescents $(19,20)$. Girls more often than boys have pro-health behaviours in food choice, choice motives, preferences, and food consumption at almost every age, which is consistent with our results (19-21). More pro-healthy food choices may be the result of higher concern about weight among women/girls than men/boys, but also of higher cultural and social engagement of women in food preparation compared to men $(21,22)$. On the other hand, the food choice motives of girls, particularly those who used different types of diets, may indicate a greater consumption of pro-healthy food products to hide risky weight behaviours (23).

We observed that in adolescents with overweight and obesity there was no difference in the consumption frequency according to age and the differences between boys and girls occurred less frequently. The differences concerned only a higher consumption of dark bread and rolls and a lower consumption of beans among girls than in boys. There were no differences in dietary fibre intake between girls and boys with overweight and obesity. Perhaps boys and girls with overweight make similar eating mistakes. Prospective studies involving three separate cohorts (n 120,877 U.S. citizens) indicated similar findings (in direction and magnitude) for men and women in dietary factors and other lifestyle factors (i.e. physical activity, sleeping duration, time spent watching television, alcohol use, or smoking) were independently related to weight change (24).

Our results did not confirm a significant difference between adolescents with normal weight and overweight in the intake of dietary fibre. Most studies indicated positive influence of dietary fibre intake in weight management, although some uncertainties remain $(7,8)$. In epidemiological studies, most of the subjects have an inadequate dietary fibre intake (8). Even after adjustment for a physiologically plausible reported energy intake, only $8 \%$ of women and $2 \%$ of men consumed dietary fibre in the amount meeting the adequate intake (AI) recommendation $(>25 \mathrm{~g} / \mathrm{d}$ and $>38 \mathrm{~g} / \mathrm{d}$, respectively) (25). The small percentage of people with sufficient fibre intake makes it difficult to correctly assess the results. Furthermore, taking into account the energy density of diets, it appears that dietary fibre intake may have an inverse as- 
Table 1. Mean values of the consumption frequencies of dietary fibre and its source in boys and girls with normal weight and overweight

\begin{tabular}{|c|c|c|c|c|}
\hline & \multicolumn{3}{|c|}{ Mean values $(95 \% \mathrm{Cl})$} & \multirow{2}{*}{$\mathrm{p}$} \\
\hline & Boys + Girls & Boys & Girls & \\
\hline \multicolumn{5}{|l|}{ Total sample } \\
\hline Sample size & 1,565 & 753 & 812 & \\
\hline Overall dietary fibre & $18.5(18.2-18.7)$ & $18.2(17.9-18.6)$ & $18.7(18.4-19.1) \downarrow$ & * \\
\hline Fruit juices & $2.46(2.40-2.52)$ & $2.41(2.32-2.49)$ & $2.51(2.42-2.59) \downarrow$ & \\
\hline Fruit & $2.61(2.55-2.67)$ & $2.50(2.42-2.58) \downarrow$ & $2.71(2.64-2.79) \downarrow$ & *** \\
\hline Fresh vegetables & $2.09(2.03-2.15)$ & $2.00(1.91-2.09)$ & $2.17(2.09-2.26)$ & ** \\
\hline Beans & $0.65(0.61-0.69)$ & $0.72(0.66-0.79)$ & $0.58(0.53-0.64)$ & ** \\
\hline Potatoes & $2.83(2.78-2.88)$ & $2.89(2.82-2.96)$ & $2.77(2.70-2.85) \downarrow$ & * \\
\hline Other vegetables & $1.74(1.69-1.80)$ & $1.70(1.62-1.78)$ & $1.78(1.70-1.87)$ & \\
\hline White bread and rolls & $3.03(2.97-3.09)$ & $3.08(3.00-3.17)$ & $2.99(2.90-3.07) \downarrow$ & \\
\hline Dark bread and rolls & $1.39(1.32-1.45)$ & $1.26(1.17-1.35)$ & $1.51(1.42-1.60) \uparrow$ & $* * *$ \\
\hline High-fibre or bran cereals & $1.68(1.62-1.74)$ & $1.64(1.55-1.73)$ & $1.71(1.63-1.80)$ & \\
\hline \multicolumn{5}{|l|}{ Normal weight } \\
\hline Sample size & 1,279 & 596 & 683 & \\
\hline Overall dietary fibre & $18.5(18.3-18.8)$ & $18.3(17.9-18.6)$ & $18.8(18.4-19.2) \downarrow$ & * \\
\hline Fruit juices & $2.48(2.41-2.55)$ & $2.43(2.33-2.52)$ & $2.52(2.43-2.62) \downarrow$ & \\
\hline Fruit & $2.62(2.56-2.69)$ & $2.52(2.43-2.61) \downarrow$ & $2.72(2.63-2.80) \downarrow$ & ** \\
\hline Fresh vegetables & $2.07(2.01-2.14)$ & $1.97(1.88-2.07)$ & $2.16(2.07-2.25)$ & ** \\
\hline Beans & $0.64(0.59-0.68)$ & $0.69(0.62-0.76)$ & $0.59(0.53-0.65)$ & * \\
\hline Potatoes & $2.85(2.79-2.91)$ & $2.91(2.83-2.99)$ & $2.79(2.71-2.88) \downarrow$ & * \\
\hline Other vegetables & $1.73(1.67-1.80)$ & $1.69(1.60-1.78)$ & $1.77(1.68-1.87)$ & \\
\hline White bread and rolls & $3.08(3.01-3.14)$ & $3.14(3.05-3.23)$ & $3.02(2.93-3.12) \downarrow$ & \\
\hline Dark bread and rolls & $1.38(1.30-1.45)$ & $1.25(1.15-1.35)$ & $1.48(1.38-1.59) \uparrow$ & ** \\
\hline High-fibre or bran cereals & $1.70(1.63-1.77)$ & $1.66(1.55-1.76)$ & $1.73(1.64-1.83)$ & \\
\hline \multicolumn{5}{|c|}{ Overweight $(n=208)$ and obese $(n=78)$} \\
\hline Sample size & 286 & 157 & 129 & \\
\hline Overall dietary fibre & $18.2(17.7-18.8)$ & $18.0(17.2-18.8)$ & $18.5(17.7-19.2)$ & \\
\hline Fruit juices & $2.37(2.22-2.53)$ & $2.33(2.13-2.53)$ & $2.43(2.20-2.66)$ & \\
\hline Fruit & $2.56(2.43-2.69)$ & $2.45(2.26-2.63)$ & $2.69(2.51-2.87)$ & \\
\hline Fresh vegetables & $2.15(2.02-2.29)$ & $2.09(1.89-2.29)$ & $2.23(2.04-2.43)$ & \\
\hline Beans & $0.71(0.60-0.82)$ & $0.85(0.69-1.01)$ & $0.54(0.41-0.68)$ & ** \\
\hline Potatoes & $2.75(2.62-2.88)$ & $2.82(2.65-3.00)$ & $2.66(2.46-2.85)$ & \\
\hline Other vegetables & $1.79(1.65-1.93)$ & $1.74(1.54-1.94)$ & $1.84(1.64-2.05)$ & \\
\hline White bread and rolls & $2.84(2.69-2.99)$ & $2.89(2.68-3.10)$ & $2.78(2.56-3.01)$ & \\
\hline Dark bread and rolls & $1.45(1.29-1.61)$ & $1.28(1.07-1.49)$ & $1.65(1.41-1.89)$ & * \\
\hline High-fibre or bran cereals & $1.60(1.46-1.74)$ & $1.58(1.38-1.78)$ & $1.63(1.42-1.83)$ & \\
\hline
\end{tabular}

Arithmetic mean values calculated from points assigned to consumption categories (from 0 pts. for less than once a week to 4 pts. for every day); dietary fibre calculated as sum of points associated with frequency categories (from 0 to 36 pts.); compared by Kruskal-Wallis test; $\downarrow \uparrow-$ increase or decrease trends of consumption with increasing age groups, compared by Spearman test; ${ }^{*} p \leq 0.05,{ }^{* *} p<0.01,{ }^{* * *} p<0.001$

sociation with BMI only among women (25). A literature review by Wanders et al. (26) indicated that in only about half of the examined articles was a higher intake of dietary fibre associated with reduction in energy intake, appetite or body weight. However, it should be emphasized that "fibre reduced body weight by $1.3 \%$ over the complete study period (on average $0.72 \mathrm{~kg}$ ), which corresponds to a reduction of $0.4 \%$ per 4 weeks" (26). "Overall, the effects on energy intake and body weight were relatively small and distinct dose-response relationships were not observed" (26). In addition, it is difficult to accurately measure the prevalence of overweight and obesity in adolescents because of the physiological changes in their bodies during puberty. The role of fibre in an aetiology of overweight among adolescents remains unclear and requires further studies. 
Table 2. Odds ratio of overweight prevalence in boys and girls with insufficient intake of dietary fibre and consumption of fibre sources $\geq 4$ times per week

\begin{tabular}{|l|c|c|c|c|}
\hline \multirow{2}{*}{} & \multicolumn{4}{|c|}{ Odds ratio (95\% CI) } \\
\cline { 2 - 5 } & \multirow{2}{*}{$\begin{array}{c}\text { Overweight and obese } \\
\text { (Reference: normal weight) }\end{array}$} & \multicolumn{3}{|c|}{ Overweight and obese adjusted by } \\
\cline { 3 - 5 } & $0.91(0.70-1.18)$ & $0.92(0.71-1.20)$ & $0.89(0.69-1.17)$ & $0.91(0.70-1.19)$ \\
\hline Insufficient intake of dietary fibre & $0.88(0.68-1.14)$ & $0.89(0.69-1.16)$ & $0.87(0.67-1.13)$ & $0.88(0.69-1.15)$ \\
\hline Fruit juices & $0.89(0.69-1.15)$ & $0.92(0.71-1.18)$ & $0.87(0.67-1.13)$ & $0.90(0.70-1.17)$ \\
\hline Fruit & $1.00(0.85-1.20)$ & $1.02(0.75-1.37)$ & $1.00(0.87-1.15)$ & $1.01(0.64-1.60)$ \\
\hline Fresh vegetables & $1.79(0.99-3.24)$ & $1.75(0.96-3.16)$ & $1.77(0.98-3.21)$ & $1.73(0.95-3.13)$ \\
\hline Beans & $0.93(0.71-1.22)$ & $0.91(0.70-1.20)$ & $0.92(0.70-1.21)$ & $0.90(0.69-1.19)$ \\
\hline Potatoes & $1.24(0.93-1.65)$ & $1.25(0.94-1.68)$ & $0.86(0.63-1.18)$ & $1.25(0.94-1.67)$ \\
\hline Other vegetables & $0.74(0.56-0.97)^{*}$ & $0.72(0.55-0.95)^{*}$ & $0.73(0.55-0.96)^{*}$ & $0.72(0.54-0.94)^{*}$ \\
\hline White bread and rolls & $1.25(0.92-1.69)$ & $1.29(0.95-1.75)$ & $1.26(0.93-1.71)$ & $1.30(0.95-1.76)$ \\
\hline Dark bread and rolls & $0.89(0.66-1.20)$ & $0.90(0.66-1.21)$ & $0.88(0.65-1.20)$ & $0.89(0.66-1.20)$ \\
\hline High-fibre or bran cereals & & \multicolumn{2}{|c|}{ Gender } & \multicolumn{2}{|c|}{ Gender and age } \\
\hline
\end{tabular}

On the basis of the sum of points assigned to consumption frequencies, the adolescents were divided into 2 groups: with insufficient fibre intake (20-29 pts.) and with fibrepoor diet (<20 pts.); the consumption frequency was divided into 2 categories: $<4$ times per week and $\geq 4$ times per week; compared by Wald test; ${ }^{*} p<0.05$

Table 3. Multiple linear regression model for dietary fibre intake and gender, age, BMI, and food sources of fibre

\begin{tabular}{|c|c|c|c|c|}
\hline & $\beta$ & SE & $\mathbf{R}^{2}$ & $\mathrm{p}$ \\
\hline MODEL & & & 0.626 & $* * * *$ \\
\hline Gender & 0.01 & 0.02 & 0.056 & ns \\
\hline Age & -0.05 & 0.02 & 0.044 & $* * *$ \\
\hline BMI & 0.02 & 0.02 & 0.039 & ns \\
\hline Fruit juices & 0.21 & 0.02 & 0.134 & $* * * *$ \\
\hline Fruit & 0.17 & 0.02 & 0.212 & $* * * *$ \\
\hline Fresh vegetables & 0.19 & 0.02 & 0.179 & $* * * *$ \\
\hline Beans & 0.13 & 0.02 & 0.090 & $* * * *$ \\
\hline Potatoes & 0.18 & 0.02 & 0.100 & $* * * *$ \\
\hline Other vegetables & 0.20 & 0.02 & 0.153 & $* * * *$ \\
\hline White bread and rolls & 0.20 & 0.02 & 0.210 & $* * * *$ \\
\hline Dark bread and rolls & 0.24 & 0.02 & 0.210 & $* * * *$ \\
\hline High-fibre or bran cereals & 0.22 & 0.02 & 0.081 & $* * * *$ \\
\hline
\end{tabular}

$\beta$ - regression coefficient (partial slope coefficient); SE - standard error; $R$ - coefficient of determination; ${ }^{* * \star} p<0.001,{ }^{* \star \star *} p<0.0001$, ns - statistically not significant

Our results indicated that a higher frequency of white bread and rolls consumption decreased the chance of occurrence of overweight and obesity by $26 \%$, which is not consistent with results reported by other researchers. A high consumption of white bread is a part of food pattern which is based mostly on soft drinks, pastry and meat, contains less favourable nutrients and is strongly associated with higher BMI values (27). However, in other Polish research among adolescents, dark bread was more often eaten by overweight young people than those with normal weight (28). In Poland, white bread is one of the most often consumed foods for breakfast (29). The regularity of eating breakfast and overall meals can be more important for weight maintenance than only having a low energy diet (28).

Although there were no significant differences in the intake of dietary fibre and most of its sources according to weight, it was found that overweight and obesity were more often prevalent among boys than among girls. The girls made pro-healthy food choices more often. Boys diet compared to girls was richer in potatoes, beans and white bread and rolls, and it resulted in lower dietary fibre intake. Girls diet contained more dietary fibre as a result of higher consumption of fruit, fresh vegetables, and dark bread and rolls. Fruit and vegetables are more liked and more often eaten by girls, while boys like more fatty and sugary foods and eat less high-fibre food and low-fat food $(19,21)$. Additionally, lower consumption of fruit and vegetables is very often associated with longer time watching $\mathrm{TV}$, overall lower energy expenditure, and increasing energy density, especially from sweet and fatty snacks $(30,31)$. Furthermore, some vegetables and baking goods are associated with higher fat intake. In Poland, potatoes are usually eaten with gravy sauce or as french-fries or puree and this may be the explanation for an increase in obesity prevalence in men with increasing consumption of potatoes $(32,33)$. Our results indicate that general eating habits could be more important in the prevention of overweight than the intake of dietary fibre and its sources considered separately. 
A limitation of the study is the lack of information on the level of physical activity and the overall energy of adolescent diet. This information was not collected during the study. The strength of the study is the large sample size, with a similar number of subjects in study groups in terms of age and sex, and balanced pattern of urbanisation of residence, which accurately reflects the structure of adolescents in Poland. This characterisation of the sample increases the strength of inference and generalisation of the results. The tools used to assess nutrition were characterized by the high reproducibility and reliability of the results (17).

\section{CONCLUSION}

Overweight was more prevalent in boys than girls since girls had higher intake of dietary fibre and healthier eating habits. Girls more often consumed fruit, fresh vegetables and dark bread and rolls, whereas boys consumed more potatoes, beans and white bread and rolls. However, the consumption frequency of dietary fibre and its sources did not have influence on the prevalence of overweight, with the exception of white bread and rolls. A higher consumption of white bread and rolls decreased the chance of overweight occurrence in adolescents. There was a decrease in the intake of dietary fibre with the increasing age of the adolescents. The consumption frequency of dietary fibre and its sources was more related to gender and age than to adolescents' weight. The role of dietary fibre in weight management is still uncertain. This study indicated that the general dietary pattern could be more important in the prevention of overweight than the separate intake of dietary fibre and its sources.

\section{REFERENCES}

1. Kelder SH, Perry CL, Klepp KI, Lytle LL. Longitudinal tracking of adolescent smoking, physical activity, and food choice behaviors. Am J Public Health. 1994 Jul;84(7):1121-6.

2. Mikkilä V, Räsänen L, Raitakari OT, Pietinen P, Viikari J. Longitudinal changes in diet from childhood into adulthood with respect to risk of cardiovascular diseases: The Cardiovascular Risk in Young Finns Study. Eur J Clin Nutr. 2004 Jul;58(7):1038-45.

3. Scaglioni S, Salvioni M, Galimberti C. Influence of parental attitudes in the development of children eating behaviour. Br J Nutr. 2008 Feb;99 Suppl 1:S22-5.

4. Birch LL, Fisher JO. Development of eating behaviors among children and adolescents. Pediatrics. 1998 Mar;101(3 Pt 2):539-49.

5. Gutkowska K, Ozimek I, editors. Behavior of young consumers on the food market. Warsaw: SGGW; 2008. (In Polish.)

6. Venn AJ, Thomson RJ, Schmidt MD, Cleland VJ, Curry BA, Gennat HC, et al. Overweight and obesity from childhood to adulthood: a follow-up of participants in the 1985 Australian Schools Health and Fitness Survey. Med J Aust. 2007 May 7;186(9):458-60.

7. Howarth NC, Saltzman E, Roberts SB. Dietary fiber and weight regulation. Nutr Rev. 2001 May;59(5):129-39.

8. Slavin JL. Dietary fiber and body weight. Nutrition. 2005 Mar;21(3):411-8.

9. Pasman WJ, Westerterp-Plantenga MS, Muls E, Vansant G, van Ree J, Saris WH. The effectiveness of long-term fibre supplementation on weight maintenance in weight-reduced women. Int J Obes Relat Metab Disord. 1997 Jul;21(7):548-55.

10. Pasman WJ, Saris WH, Wauters MA, Westerterp-Plantenga MS. Effect of one week of fibre supplementation on hunger and satiety ratings and energy intake. Appetite. 1997 Aug;29(1):77-87.

11. Wądołowska L. Nutritional basis of the health risk in Poland. Olsztyn: University of Warmia-Mazury; 2010. (In Polish.)

12. Reicks M, Jonnalagadda S, Albertson AM, Joshi N. Total dietary fiber intakes in the US population are related to whole grain consumption: results from the National Health and Nutrition Examination Survey 2009 to 2010. Nutr Res. 2014 Mar;34(3):226-34.

13. Larson NI, Neumark-Sztainer D, Hannan PJ, Story M. Trends in adolescent fruit and vegetable consumption, 1999-2004: project EAT. Am J Prev Med. 2007 Feb;32(2):147-50.

14. Lock K, Pomerleau J, Causer L, Altmann DR, McKee M. The global burden of disease attributable to low consumption of fruit and vegetables: implications for the global strategy on diet. Bull World Health Organ. $2005 \mathrm{Feb} ; 83(2): 100-8$

15. Rolls BJ, Ello-Martin JA, Tohill BC. What can intervention studies tell us about the relationship between fruit and vegetable consumption and weight management? Nutr Rev. 2004 Jan;62(1):1-17.

16. Kułaga Z, Litwin M, Tkaczyk M, Palczewska I, Zajączkowska M, Zwolińska D, et al. Polish 2010 growth references for school-aged children and adolescents. Eur J Pediatr. 2011 May;170(5):599-609.

17. Thompson FE, Byers T. Dietary assessment resource manual. J Nutr. 1994 Nov;124(11 Suppl):2245S-2317S.

18. McGill CR, Fulgoni VL 3rd, Devareddy L. Ten-year trends in fiber and whole grain intakes and food sources for the United States population: National Health and Nutrition Examination Survey 2001-2010. Nutrients. 2015 Feb 9;7(2):1119-30.

19. Cooke LJ, Wardle J. Age and gender differences in children's food preferences. Br J Nutr. 2005 May;93(5):741-6.

20. Wądołowska L, Babicz-Zielińska E, Czarnocińska J. Food choice models and their relation with food preferences and eating frequency in the Polish population. POFPRES study. Food Policy. 2008;33(2):122-34.

21. Wardle J, Haase AM, Steptoe A, Nillapun M, Jonwutiwes K, Bellisle F. Gender differences in food choice: the contribution of health beliefs and dieting. Ann Behav Med. 2004 Apr;27(2):107-16.

22. McCabe MP, Ricciardelli LA. Body image dissatisfaction among males across the lifespan: a review of past literature. J Psychosom Res. 2004 Jun;56(6):675-85.

23. Lattimore PJ, Halford JC. Adolescence and the diet-dieting disparity: healthy food choice or risky health behaviour? Br J Health Psychol. 2003 Nov;8(Pt 4):451-63.

24. Mozaffarian D, Hao T, Rimm EB, Willett WC, Hu FB. Changes in diet and lifestyle and long-term weight gain in women and men. N Engl J Med. 2011 Jun 23;364(25):2392-404.

25. Howarth NC, Huang TT, Roberts SB, McCrory MA. Dietary fiber and fat are associated with excess weight in young and middle-aged US adults. J Am Diet Assoc. 2005 Sep;105(9):1365-72.

26. Wanders AJ, van den Borne JJ, de Graaf C, Hulshof T, Jonathan MC, Kristensen M, et al. Effects of dietary fibre on subjective appetite, energy intake and body weight: a systematic review of randomized controlled trials. Obes Rev. 2011 Sep;12(9):724-39.

27. Wirfält AK, Jeffery RW. Using cluster analysis to examine dietary patterns: nutrient intakes, gender, and weight status differ across food pattern clusters. J Am Diet Assoc. 1997 Mar;97(3):272-9.

28. Jodkowska M, Oblacińska A, Tabak I, Radiukiewicz K. Differences in dietary patterns between overweight and normal-weight adolescents. Med Wieku Rozwoj. 2011 Jul-Sep;15(3):266-73.

29. Wojtyła-Buciora P, Stawińska-Witoszyńska B, Klimberg A, Wojtyła A, Goździewska M, Wojtyła K, et al. Nutrition-related health behaviours and prevalence of overweight and obesity among Polish children and adolescents. Ann Agric Environ Med. 2013;20(2):332-40.

30. Lowry R, Wechsler H, Galuska DA, Fulton JE, Kann L. Television viewing and its associations with overweight, sedentary lifestyle, and insufficient consumption of fruits and vegetables among US high school students: differences by race, ethnicity, and gender. J Sch Health. 2002 Dec;72(10):413-21.

31. Janssen I, Katzmarzyk PT, Boyce WF, Vereecken C, Mulvihill C, Roberts C, et al.; Health Behaviour in School-Aged Children Obesity Working Group. Comparison of overweight and obesity prevalence in school-aged youth from 34 countries and their relationships with physical activity and dietary patterns. Obes Rev. 2005 May;6(2):123-32.

32. Lin BH, Morrison RM. Higher fruit consumption linked with lower body mass index. Food Rev. 2002;25(3):28-32.

33. Krebs NF, Himes JH, Jacobson D, Nicklas TA, Guilday P, Styne D. Assessment of child and adolescent overweight and obesity. Pediatrics. 2007 Dec;120 Suppl 4:S193-228. 